\title{
In Situ Assessment of the Brain Microcirculation in Mechanically- Ventilated Rabbits Using Sidestream Dark-Field (SDF) Imaging
}

\author{
M. ŠITINA ${ }^{1}$, Z. TUREK ${ }^{2}$, R. PAŘÍZKOVÁ², V. ČERNÝ ${ }^{2,3}$ \\ ${ }^{1}$ Department of Gerontology and Metabolism, and ${ }^{2}$ Department of Anesthesiology and Intensive \\ Care Medicine, Charles University in Prague, Faculty of Medicine in Hradec Kralove, University \\ Hospital Hradec Kralove, Czech Republic, ${ }^{3}$ Department of Anesthesia, Dalhousie University, \\ Halifax, Canada
}

Received November 30, 2009

Accepted May 26, 2010

On-line October 15, 2010

\begin{abstract}
Summary
Assessment of the cerebral microcirculation by on-line visualization has been impossible for a long time. Sidestream dark-field (SDF) imaging is a relatively new method allowing direct visualization of cerebral surface layer microcirculation using hand-held probe for direct contact with target tissue. The aim of this study was to elucidate the feasibility of studying the cerebral microcirculation in situ by SDF imaging and to assess the basic cerebral microcirculatory parameters in mechanically ventilated rabbits. Images were obtained using SDF imaging from the surface of the brain via craniotomy. Clear high contrast SDF images were successfully obtained. Total small-vessel density was $14.6 \pm 1.8 \mathrm{~mm} / \mathrm{mm}^{2}$, total all-vessel density was $17.9 \pm 1.7$ $\mathrm{mm} / \mathrm{mm}^{2}$, DeBacker score was $12.0 \pm 1.6 \mathrm{~mm}^{-1}$ and microvascular flow index was $3.0 \pm 0.0$. This method seems to be applicable in animal studies with possibility to use SDF imaging also intraoperatively, providing unique opportunity to study cerebral microcirculation during various experimental and clinical settings.
\end{abstract}

\section{Key words}

SDF imaging • Brain perfusion • Microcirculation • Rabbits

\section{Corresponding author}

Michal Sitina, Department of Gerontology and Metabolism, Charles University in Prague, Faculty of Medicine in Hradec Kralove, University Hospital Hradec Kralove, Sokolska 581, 50005 Hradec Kralove, Czech Republic. E-mail: sitinmi0@fnhk.cz

\section{Introduction}

There is an increasing evidence to suggest the critical role of the microcirculation in many pathological conditions (Elberts and Ince 2006, Ellis et al. 2005, den Uil 2008). Also, normal macrocirculatory parameters do not preclude a significant alteration of microcirculation (Boerma et al. 2005).

Several technologies are available for intravital visualization of microcirculation. Those most often used are intravital microscopy (IVM), orthogonal polarization spectral (OPS) imaging, sidestream dark-field (SDF) imaging and laser Doppler flowmetry (DeBacker and Dubois 2001). OPS imaging and its successor SDF imaging are relatively new noninvasive optical methods based on similar principles (Groner et al. 1999, Schiessler et al. 2002, DeBacker 2003, Ince 2005, Černý et al. 2007). Briefly, in SDF imaging (Ince 2005), green nonpolarized light, emitted by a ring of diodes at the tip of the light guide, directly illuminates the tissue. This light is optically isolated from the light returning from the tissue through a light guide, which prevents light reflection from the surface of the tissue. Because green light is absorbed by hemoglobin, vessels appear as dark structures on a light background. SDF technology provides improved resolution and clarity of images compared to OPS imaging (Goedhadt et al. 2007). Validation studies showed significant agreement between the data obtained from the new optical technologies and IVM (Černý et al. 2007).

Although the microcirculations of several organs have been widely studied (den Uil 2008), there exist only a limited number of studies dealing with cerebral microcirculation. 
The purpose of our study was to elucidate whether SDF imaging can be used for direct imaging of cerebral microcirculation, and to assess the basic cerebral microcirculatory parameters in mechanically-ventilated rabbits. We compared our results with those from other studies of cerebral microcirculation.

\section{Methods}

\section{Animals}

All experimental procedures were performed after Ethical Board approval in accordance with Czech legislation on the protection of animals. Seven female rabbits (Bio-Test, Konarovice, Czech Republic), weighing 3.0-4.0 kg, were included in the study. They were housed in a standard cage at $21^{\circ} \mathrm{C}$ on a $12 \mathrm{hr}$ dark/12 hr light cycle with unrestricted amounts of laboratory chow and tap water. After a one-week acclimatization period, the rabbits were enrolled into the study.

\section{Anaesthesia and surgical preparation}

After overnight fasting with unrestricted access to tap water, the rabbits were anesthetized with an intramuscular induction dose of ketamine $(50 \mathrm{mg} / \mathrm{kg})$ and xylazine $(4 \mathrm{mg} / \mathrm{kg})$. The animals were placed in the supine position on an operating table. The right central ear artery and two marginal ear veins were cannulated with polyethylene catheter for continuous blood pressure monitoring, arterial blood gas analysis and continuous infusion of fluids (normal saline, $10 \mathrm{ml} / \mathrm{kg} /$ hour), anesthesia (fentanyl $0.5 \mu \mathrm{g} / \mathrm{kg} / \mathrm{min}$, midazolam $33 \mu \mathrm{g} / \mathrm{kg} / \mathrm{min}$, propofol $0.1 \mathrm{mg} / \mathrm{kg} / \mathrm{min}$ ) and muscle relaxant (pipecuronium bromide $0.6 \mathrm{mg} / \mathrm{kg} / \mathrm{hour}$ ). The animals were tracheotomized and mechanically ventilated (Harvard Scientific ventilator, Boston, USA, ventilatory setting: tidal volume $=8 \mathrm{ml} / \mathrm{kg}, \mathrm{PEEP}=0 \mathrm{~cm} \mathrm{H}_{2} \mathrm{O}$, respiratory rate $=30 / \mathrm{min}, \mathrm{FiO}_{2}=0.21$ ). Adequacy of ventilation was verified by arterial blood gas analysis. Mean arterial blood pressure (MAP), heart rate and rectal temperature were recorded throughout the study. Rectal temperature was kept at $38.5-39.5^{\circ} \mathrm{C}$ by use of a heating plate.

Each animal was subsequently rotated to the prone position and the right temporo-parieto-occipital area of the head was shaved. The skin and periosteum of the shaved area of the skull were incized and reflected. The margins of the exposed area, with dimensions of about $1.5 \mathrm{~cm} \times 1.5 \mathrm{~cm}$, were formed by the midline, base of the right ear, external occipital protuberance and right caudal supraorbital process. Three $3 \mathrm{~mm}$ holes were drilled through the exposed skull and rests of bone were broken off with small Pean forceps. The dimensions of the created cranial window were about $12 \mathrm{~mm} \times 10 \mathrm{~mm}$, with intact arachnoid mater at the base of the window. Bleeding from the diploe was stopped by use of bone wax. The wound was covered with cotton swabs saturated with sterile $37^{\circ} \mathrm{C}$ warmed normal saline. After the control of bleeding and a 30 minute stabilization period with higher intake of fluids $(20 \mathrm{ml} / \mathrm{kg} /$ hour of normal saline), extremely careful incision of arachnoid mater was performed, which exhibited the temporo-parietal surface of the right hemisphere of forebrain. SDF probe was immediately attached to the brain surface and imaging was performed.

\section{Sidestream dark-field imaging procedure}

To minimize pressure and movement artifacts, the SDF imaging probe (MicroScan Video Microscope, Microvision Medical, Inc., Amsterdam, The Netherlands) was attached to a custom-made (Arrow International Czech Republic, a.s.) flexible arm with special adapter allowing both micromovement of the SDF probe in various axes and proper stabilization of the probe at the same time (Fig. 1). In an effort to standardize the SDF imaging of the microcirculation as much as possible, the following procedure was established. Once a sector for imaging had been selected, the SDF imaging probe was placed approximately $0.5 \mathrm{~mm}$ above the target tissue using a the flexible arm. The arm was then fixed and the probe, covered with a plastic sheath, was moved towards the tissue using the adapter for micromovement. As soon as there was contact with the brain surface, the focus ring of the probe was used to bring the proper layer into focus to create a sharp and high-contrast image. The sites of interest on the surface of the brain were selected randomly. Any exposed tissues, apart from those covered by the SDF imaging probe at any given moment, were intermittently moisturized using ad hoc drops of sterile normal saline at $37{ }^{\circ} \mathrm{C}$. For each animal, SDF images were obtained from two different areas (fields) within the site of interest. All SDF imaging data of the microcirculation were digitally recorded. All imaging procedures were performed during 2-3 minutes after incision of arachnoid mater. At the end of the experiment the animal was sacrificed with an overdose of potassium chloride. 


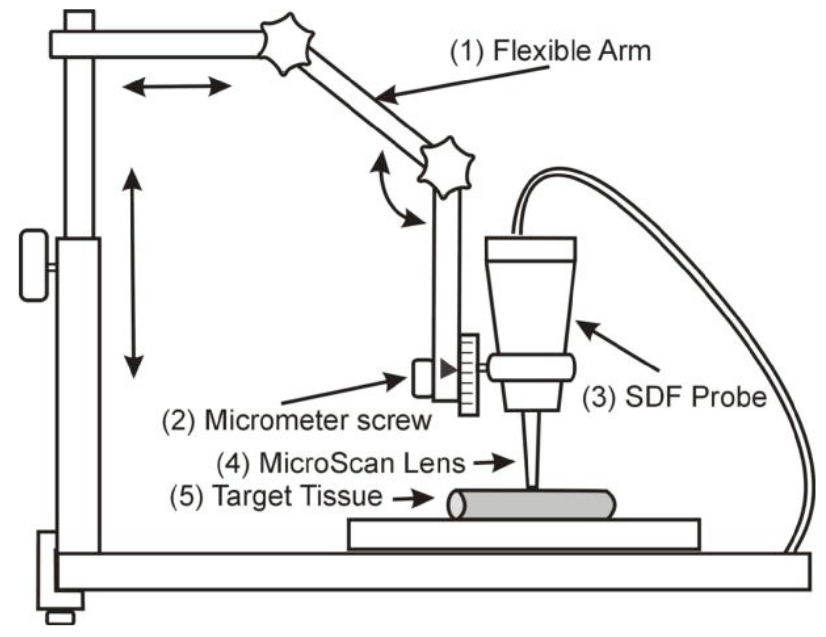

Fig. 1. A scheme of the stabilizing and fixation device for SDF imaging probe. (1) Flexible arm allowing horizontal, vertical and rotating movements ends with a special adapter with (2) micrometer screw for movement of the SDF probe (3) with MicroScan lens (4) within the range of $0,5 \mathrm{~mm}$ towards the target tissue (5).

\section{Off-line analysis}

Selection of the most stable clips with clear images for final analysis was carried out off-line. A total of 6 selected clips (3 clips for each area) of 10 seconds duration were analyzed per each animal, and their average was used for subsequent calculations. The final on-screen magnification of the images obtained with the SDF imaging device was 325 times original and the real size of the field of evaluation was $1280 \mu \mathrm{m} \times 960 \mu \mathrm{m}$. Micro-circulatory parameters were measured using AVA V3.0 software (AMC, University of Amsterdam, The Netherlands). The software is able of automatic detection of vessels and calculation of their parameters - diameter, length, density and other calculated parameters. Researcher can control this automatic process and, if the detection of vessels is not correct, make manual corrections before further calculation.

The following parameters were analyzed off-line:

1. Total small- and all-vessel density, defined as the total length of small or all vessels inside image divided by the total area of image, given in $\mathrm{mm} / \mathrm{mm}^{2}$ (DeBacker et al. 2007)

2. DeBacker score, given in $\mathrm{mm}^{-1}$, is calculated as a number of vessels crossing three arbitrary horizontal and three vertical equidistant lines (drawn on the screen) divided by the total length of the lines (DeBacker et al. 2007)

3. Microvascular flow index, which is an averaged value of semiquantitative score $(0-$ absent flow, $1-$ intermittent flow, 2 - continuous sluggish (slow) flow, 3 - continuous normal (fast) flow) of microvascular flow in four quadrants of image, assesed subjectively by observer (DeBacker et al. 2007)

4. Length-weighted vessel diameter distribution, where the value for a given range of diameters is calculated as the percentage ratio of the total length of vessels of the particular diameter range to the total length of all vessels, given in $\%$

5. Area-weighted vessel diameter distribution, where the value for a given range of diameters is calculated as the percentage ratio of the total area of vessels of the particular diameter range to the total area of all vessels, given in \%.

Small vessels are defined by diameter less than $25 \mu \mathrm{m}$. "Area of vessel" is the area of a vessel projected onto the plane of the SDF image.

\section{Statistics}

The descriptive data are presented as mean \pm standard error of mean. Statistical analyses were performed with the aid of SIGMASTAT 2.0 (Jandel Scientific, San Rafael, CA, USA). Normality of data was verified with Kolmogorov-Smirnov test.

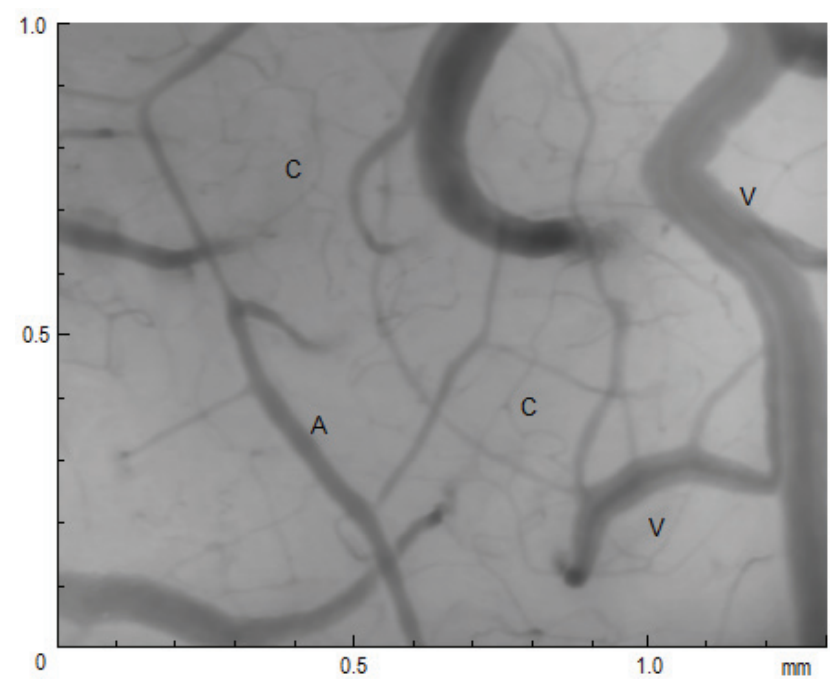

Fig. 2. Sidestream dark-field (SDF) representative image of the rabbit cerebral microcirculation. Objective $5 \times$, on screen $325 \times$, size of image $1280 \mu \mathrm{m} \times 960 \mu \mathrm{m}$. A - arteriole, V - venule, C - capillary.

\section{Results}

A total of 7 rabbits were used in this study. The main cardiovascular parameters were stable throughout the study with MAP of $71 \pm 4 \mathrm{mmHg}$. With the special 


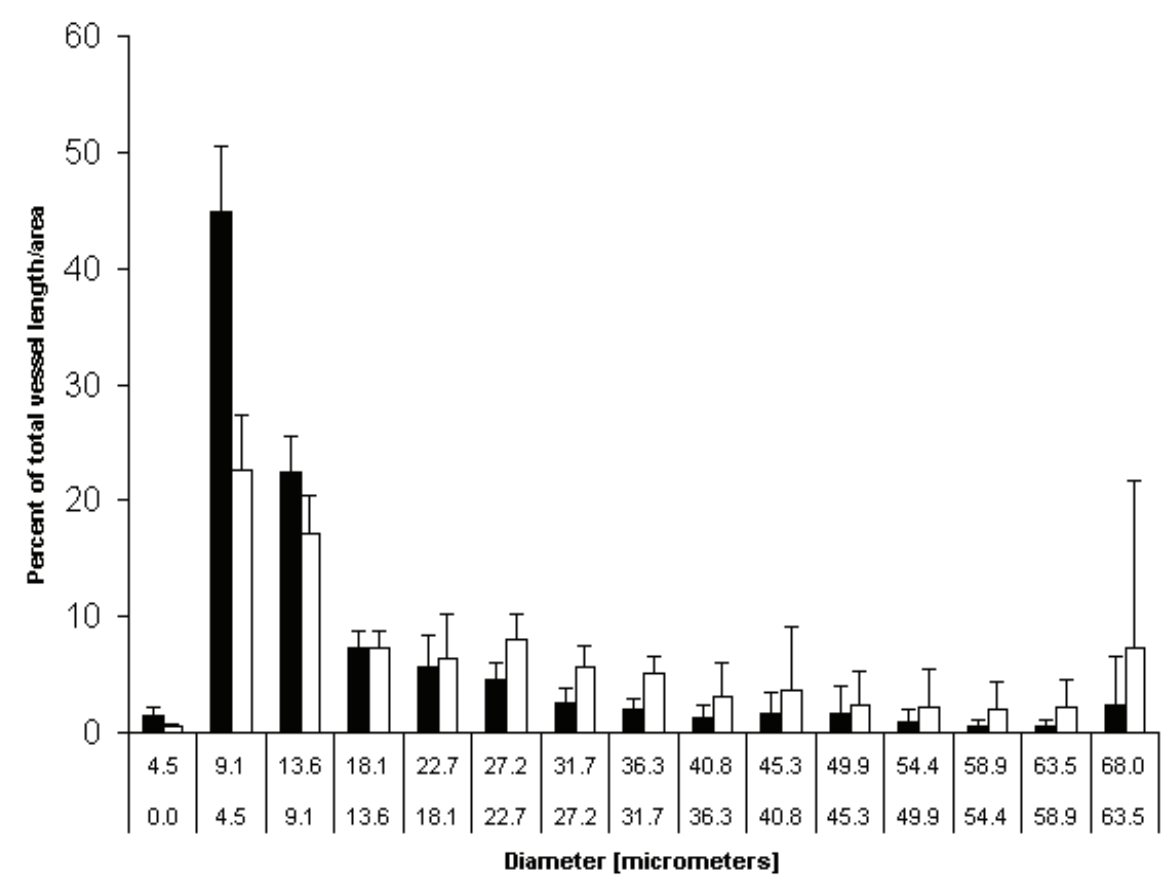

Fig. 3. Length and area weighted vessel diameter distribution. Full columns - length weighted distribution, empty columns - area weighted distribution. Value for a given range of diameters indicates percent of total length/area of vessels of the particular diameter of the total length/area of all vessels, given in \%.

custom-made fixation device for the SDF probe, clear high contrast images were successfully obtained from the surface of the rabbit brain in situ using SDF imaging technology. The morphological structures of the cerebral microvasculature were clearly identified and it was possible to perform basic off-line quantitative measurements of microcirculatory parameters. A typical image captured using SDF imaging is shown in Fig. 2. The total small-vessel density was $14.6 \pm 1.8 \mathrm{~mm} / \mathrm{mm}^{2}$, total all-vessel density was $17.9 \pm 1.7 \mathrm{~mm} / \mathrm{mm}^{2}$, DeBacker score was $12.0 \pm 1.6 \mathrm{~mm}^{-1}$ and microvascular flow index was 3.0 \pm 0.0 . Length- and area-weighted vessel diameter distributions are shown in Fig. 3.

\section{Discussion}

This study has confirmed the reliability and accuracy of SDF imaging for assessing rabbit cerebral microcirculation.

Table 1 summarizes values of microcirculatory parameters available from studies dealing with intravital cerebral microcirculation morphology found in PUBMED (Ben Mime et al. 2005, Duebener et al. 2001, Hudetz 1997, Hudetz et al. 1997, Hudetz et al. 1995, Kroppenstedt et al. 2003, Pennings et al. 2004, Pennings et al. 2006, Pérez-Bárcena et al. 2009, Ristagno et al. 2007, Ristagno et al. 2009, Thomale et al. 2001, Wan et al. 2009). Various parameters have been measured in various species (rat, pig, human) using various methods. This makes it therefore rather difficult to compare these data. No intravital imaging of rabbit cerebral microcirculation has been published so far.

In our study we measured vessels of arteriolar or venular diameter, but we did not distinguish between arterioles and venules. Although the visible flow of erythrocytes on the SDF image permits the distinction between arterioles and venules, it is not easy, if at all possible, to settle from the image the border between the capillaries and the arterioles and venules. If these types of microvessels are defined by a range of diameters, „diameter“ of arterioles or venules, as presented in the studies in Table 1, is a weighted average of a range of diameters. Instead of a specific "diameter", we present the distribution of vessel diameters according to the length or area of corresponding vessel segments on SDF image. This can provide a more detailed and comprehensive picture of vessel diameters in the microcirculation. The weighted average of any range of diameters can be calculated. For example, the calculated length-weighted average of all vessels (both arterioles and venules) with diameter greater than 10 micrometers is $30.0 \mu \mathrm{m}$, which lies between the literary values for rat (15 and $24 \mu \mathrm{m}$ for arterioles and venules (Kroppenstedt et al. 2003)) and human (53 and $51 \mu \mathrm{m}$ for arterioles and venules (Pennings et al. 2004)).

The only other study presenting the distribution of vessel diameters is that of Pérez-Bárcena (PérezBárcena et al. 2009). After adjustment of the distribution class borders (Table 2), we observed a very similar distribution. Although the experimental species (human 
Table 1. Summary of microcirculatory parameters available from studies dealing with intravital cerebral microcirculation morphology found in PUBMED.

\begin{tabular}{|c|c|c|c|c|c|}
\hline Study & Species & Method & $\begin{array}{l}\text { Diameter } \\
(\mu \mathrm{m})\end{array}$ & $\begin{array}{l}\text { Velocity } \\
(\mathrm{mm} / \mathrm{s})\end{array}$ & Other \\
\hline Ben Mime et al. 2005 & pig & IVM & & & \\
\hline Duebener et al. 2001 & pig & IVM & & & \\
\hline Hudetz et al. 1997 & rat & IVM & & C 0.6 & \\
\hline Hudetz et al. 1995 & rat & IVM & & C $1.47 \pm 0.58$ & \\
\hline Hudetz 1997 & & IVM & & C $0.5-1.8$ & \\
\hline Kroppenstedt et al. 2003 & rat & OPS & A $15, \mathrm{~V} 24$ & $\mathrm{~V} 0.5, \mathrm{~A} 4$ & \\
\hline Thomale et al. 2001 & rat & OPS & $\begin{array}{l}\text { A } 19.1 \pm 2.7 \\
\text { V } 22.2 \pm 1.4\end{array}$ & V $0.68 \pm 0.08$ & \\
\hline Pennings et al. 2004 & human & OPS & $\begin{array}{l}\text { A } 53 \pm 39 \\
\text { V } 51 \pm 48\end{array}$ & & \\
\hline Pennings et al. 2006 & human & OPS & $\begin{array}{l}\text { A } 53 \pm 39 \\
\text { V } 51 \pm 48\end{array}$ & & $\begin{array}{l}\text { Functional C density } 30 \pm 0.5 \\
\text { MFI } 3\end{array}$ \\
\hline Ristagno et al. 2007 & pig & OPS & & & $\begin{array}{l}\text { Number of perfused C } 15 \\
\text { MFI } 3\end{array}$ \\
\hline Ristagno et al. 2009 & pig & OPS & & & $\begin{array}{l}\text { Number of perfused C } 15 \\
\text { MFI } 3\end{array}$ \\
\hline Wan et al. 2009 & rat & SDF & & & $\begin{array}{l}\text { Perfused vessel percent } 98 \\
\text { MFI } 3 \\
\text { DeBacker score } 5.0\end{array}$ \\
\hline Pérez-Bárcena et al. 2009 & human & SDF & & & Distribution \\
\hline
\end{tabular}

A - arterioles, V - venules, C-capillaries, IVM - intravital microscopy, OPS - orthogonal polarization spectral imaging, SDF - sidestream dark-field imaging, MFI - microvascular flow index.

Table 2. Comparison of length weighted vessel diameter distribution in our study and the study of Pérez-Bárcena.

\section{Vessel diameter Percent of total vessel length} Pérez-Bárcena et al. 2009 Our study

\begin{tabular}{lcc}
$0-20 \mu \mathrm{m}$ & 77.9 & 81.6 \\
$20-40 \mu \mathrm{m}$ & 12.3 & 10.4 \\
$40-60 \mu \mathrm{m}$ & 6.7 & 5.7 \\
over $60 \mu \mathrm{m}$ & 3.1 & 2.9 \\
\hline
\end{tabular}

versus rabbit) were different in both studies, the relative distribution of diameters is almost the same, which suggests that the architecture of the cerebral surface microcirculation is similar.

We did not index all individual vessels visible on SDF image with Boerma indexes (DeBacker et al. 2007). We were therefore unable to calculate perfused (resp. functional) vessel density and percentage of perfused vessels according to the consensus conference (DeBacker et al. 2007). As an approximate surrogate for these parameters we can combine total (small-) vessel density and microvascular flow index (MFI). Because MFI was 3.0 in all measurements, indexing of all individual vessels would result in perfused densities approaching the total densities. In the study of Pennings (Pennings et al. 2006) in humans, functional capillary density, corresponding to small-vessel density in our study, was $30 \pm 5 \mathrm{~mm} / \mathrm{mm}^{2}$, versus $14.6 \pm 1.8 \mathrm{~mm} / \mathrm{mm}^{2}$ in our study. One would intuitively expect such a somewhat higher value for human than for rabbit cerebral surface microcirculation.

During each recording, we observed microcirculation for about 10 seconds. In preliminary phase of experiment, we also performed observations longer than 60 seconds, but we did not detect any significant changes with time. We, therefore, consider observations for 10 seconds as sufficient. This period is also mentioned in the papers using the same technology.

Rabbit was chosen for this experiment because 
of the optimal compromise between the dimension of the head of animal and the size of the SDF probe. The head (and so the brain) of smaller animals, such as rats, has a similar dimension to that of the SDF probe, which results in need the need for a relatively wide craniotomy with all the attendant technical difficulties (especially intraoperative bleeding from diploe). It is also even more difficult to obtain images from more than two or three (as is recommended according to consensual conference (DeBacker et al. 2007)) areas of the cerebral surface, because the tip of the SDF probe just fits into the craniotomy. On the other hand, a larger animal, such as a pig, consumes a higher quantity of anesthetics and other medication, which increases the costs of experiment, without additional benefit of the larger dimension. We thus consider rabbit as an ideal animal for the study of the cerebral microcirculation using SDF technology.

Our study has several limitations.

Pressure artifacts attributable to the SDF probe are a problem common to all contact techniques (Lindert et al. 2002). We used a very careful method of obtaining of the SDF image as described above in an effort to minimize this type of artifact. One of the advantages of SDF imaging as opposed to OPS imaging is the fact that the tip of the SDF probe is fixed during focusing (Goedhadt et al. 2007).

Lateral movement of the tissue is another general limitation of the SDF method, interfering especially with measurement of flow velocities. A special custom-made device allowing micromovement of the SDF probe was used in this study. The advantage of brain surface imaging is the quite stable position of the tissue in the head, which further minimizes lateral movements during imaging.

Artifacts are also generated by puncturing the arachnoid mater. In the study of Thomale (Thomale et al.
2001) performed in on rats, the arachnoid mater was not opened, and the SDF imaging was performed through it. In the case of rabbits, the presence of the arachnoid mater significantly decreases the visual sharpness of the surface cerebral vessels and practically disables transarachnoid SDF imaging, possibly because of thicker arachnoid mater and a wider subarachnoid space than in rats. After opening of the arachnoid mater, the brain surface was intermittently moistened with saline of body temperature; any adverse influence of this moistening on cerebral microcirculation cannot be fully excluded. On the other hand, all imaging procedures were performed during 2-3 minutes after arachnoid mater incision, when brain surface was still covered by rests of cerebrospinal fluid. We hope therefore, that artifacts induced by use of saline were not significant. In case of longer use, however, these artifacts would be critical.

In summary, we confirmed the reliability and accuracy of SDF imaging for assessing rabbit cerebral microcirculation and measure basic microcirculatory parameters which are comparable with the measurements of other authors. Our results can be used as a reference for future studies of cerebral microcirculation on the rabbit model. This method seems to be applicable in animal studies with possibility to use SDF imaging also intraoperatively, providing unique opportunity to study cerebral microcirculation in various experimental and clinical settings.

\section{Conflict of Interest}

There is no conflict of interest.

\section{Acknowledgements}

Research project MZO 00179906. Arrow International Czech Republic for special custom made SDF probe holder.

\section{References}

BEN MIME L, ARNHOLD S, FISCHER JH, ADDICKS K, RAINER DE VIVIE E, BENNINK G, SUEDKAMP M: Pharmacologic cerebral capillary blood flow improvement after deep hypothermic circulatory arrest: an intravital fluorescence microscopy study in pigs. J Thorac Cardiovasc Surg 130: 670-676, 2005.

BOERMA EC, VAN DER VOORT PH, INCE C: Sublingual microcirculatory flow is impaired by the vasopressinanalogue terlipressin in a patient with catecholamine-resistant septic shock. Acta Anaesthesiol Scand 49: 13871390, 2005.

ČERNÝ V, TUREK Z, PAŘÍZKOVÁ R: Orthogonal polarization spectral imaging. Physiol Res 56: 141-147, 2007.

DE BACKER D: OPS techniques. Minerva Anesthesiol 69: 388-391, 2003.

DE BACKER D, DUBOIS MJ: Assessment of the microcirculatory flow in patients in the intensive care unit. Curr Opin Crit Care 7: 200-203, 2001. 
DE BACKER D, HOLLENBERG S, BOERMA C, GOEDHART P, BÜCHELE G, OSPINA-TASCON G, DOBBE I, INCE C: How to evaluate the microcirculation: report of a round table conference. Crit Care 11: R101, 2007.

DEN UIL CA, KLIJN E, LAGRAND WK, BRUGTS JJ, INCE C, SPRONK PE, SIMOONS ML: The microcirculation in health and critical disease. Prog Cardiovasc Dis 51: 161-170, 2008.

DUEBENER LF, SAKAMOTO T, HATSUOKA S, STAMM C, ZURAKOWSKI D, VOLLMAR B, MENGER MD, SCHÄFERS HJ, JONAS RA: Effects of hematocrit on cerebral microcirculation and tissue oxygenation during deep hypothermic bypass. Circulation 104 (Suppl 1): I260-I264, 2001.

ELBERS PW, INCE C: Mechanisms of critical illness - classifying microcirculatory flow abnormalities in distributive shock. Crit Care 10: 221, 2006.

ELLIS CG, JAGGER J, SHARPE M: The microcirculation as a functional system. Crit Care 9 (Suppl 4): S3-S8, 2005.

GOEDHART PT, KHALILZADA M, BEZEMER R, MERZA J, INCE C: Sidestream Dark Field (SDF) imaging: a novel stroboscopic LED ring-based imaging modality for clinical assessment of the microcirculation. Opt Express 15: 15101-15114, 2007.

GRONER W, WINKELMAN JW, HARRIS AG, INCE C, BOUMA GJ, MESSMER K, NADEAU RG: Orthogonal polarization spectral imaging: a new method for study of the microcirculation. Nat Med 5: 1209-1212, 1999.

HUDETZ AG: Blood flow in the cerebral capillary network: a review emphasizing observations with intravital microscopy. Microcirculation 4: 233-252, 1997.

HUDETZ AG, BISWAL BB, FEHÉR G, KAMPINE JP: Effects of hypoxia and hypercapnia on capillary flow velocity in the rat cerebral cortex. Microvasc Res 54: 35-42, 1997.

HUDETZ AG, FEHÉR G, WEIGLE CG, KNUESE DE, KAMPINE JP. Video microscopy of cerebrocortical capillary flow: response to hypotension and intracranial hypertension. Am J Physiol 268: H2202-H2210, 1995.

INCE C: Sidestream dark-field (SDF) imaging: an improved technique to observe sublingual microcirculation. Crit Care 8 (Suppl): P72, 2005.

KROPPENSTEDT SN, THOMALE UW, GRIEBENOW M, SAKOWITZ OW, SCHASER KD, MAYR PS, UNTERBERG AW, STOVER JF: Effects of early and late intravenous norepinephrine infusion on cerebral perfusion, microcirculation, brain-tissue oxygenation, and edema formation in brain-injured rats. Crit Care Med 31: 2211-2221, 2003.

LINDERT J, WERNER J, REDLIN M, KUPPE H, HABAZETTL H, PRIES AR: OPS imaging of human circulation: a short technical report. $J$ Vasc Res 39: 368-372, 2002.

PENNINGS FA, BOUMA GJ, INCE C: Direct observation of the human cerebral microcirculation during aneurysm surgery reveals increased arteriolar contractility. Stroke 35: 1284-1288, 2004.

PENNINGS FA, INCE C, BOUMA GJ: Continuous real-time visualization of the human cerebral microcirculation during arteriovenous malformation surgery using orthogonal polarization spectral imaging. Neurosurgery 59: 167-171, 2006.

PÉREZ-BÁRCENA J, IBÁÑEZ J, BRELL M, LLINÁS P, ABADAL JM, LLOMPART-POU JA: Study of a brain microcirculation in cranioencephalic trauma using the Side Stream Field (SDF) system. Med Intensiva 33: 256259, 2009.

RISTAGNO G, SUN S, TANG W, CASTILLO C, WEIL MH: Effects of epinephrine andvasopressin on cerebral microcirculatory flows during and after cardiopulmonary resuscitation. Crit Care Med 35: 2145-2149, 2007.

RISTAGNO G, TANG W, HUANG L, FYMAT A, CHANG YT, SUN S, CASTILLO C, WEIL MH: Epinephrine reduces cerebral perfusion during cardiopulmonary resuscitation. Crit Care Med 37: 1408-1415, 2009.

SCHIESSLER C, SCHAUDIG S, HARRIS AG, CHRIST F: Orthogonal polarization spectral imaging - a new clinical method for monitoring of microcirculation. Anaesthesist 51: 576-579, 2002.

THOMALE UW, SCHASER KD, UNTERBERG AW, STOVER JF: Visualization of rat pial microcirculation using the novel orthogonal polarized spectral (OPS) imaging after brain injury. J Neurosci Methods 108: 85-90, 2001.

WAN Z, RISTAGNO G, SUN S, LI Y, WEIL MH, TANG W: Preserved cerebral microcirculation during cardiogenic shock. Crit Care Med 37: 2333-2337, 2009. 